\title{
Anomalous origin of left coronary artery from pulmonary artery Surgical considerations in the adult
}

\author{
K. G. Barrand, I. A. B. Brooksby, M. M. Webb-Peploe, and M. V. Braimbridge \\ From the Departments of Radiology and Cardiothoracic Surgery, St. Thomas' Hospital, London
}

The usually recommended treatment for anomalous origin of a left coronary artery from the pulmonary artery is proximal ligation of the anomalous artery with a saphenous vein bypass graft to restore aortocoronary continuity. In an adult patient with large collateral vessels and with the left coronary artery arising from the back of the pulmonary artery, the technical surgical problems associated with this procedure are formidable. Closure of the orifice of the anomalous left coronary artery from inside the pulmonary artery is suggested as the treatment of choice in such a case.

Origin of the left coronary artery from the pulmonary artery was first described by Brooks in I886, and first linked with a clinical syndrome by Bland, White, and Garland (1933). It is a rare anomaly affecting I in 300,000 children (Keith, 1959), I5 per cent of whom survive to adult life. The survivors are those with a big collateral circulation which enables the right coronary artery to supply both ventricles in addition to the flow lost into the pulmonary artery (Hudson, 1965).

In the adult patient this collateral flow may be very large. The surgical problems posed by such a shunt from aorta to pulmonary artery are emphasized by the following case report.

\section{Case report}

A 22-year-old Jamaican woman was first noticed to have a heart murmur during her first pregnancy in 1967. She became dyspnoeic during subsequent pregnancies and in 1972 her fourth pregnancy was terminated because of episodes of paroxysmal nocturnal dyspnoea. After this she suffered with dyspnoea (NYHA grade 3), ankle oedema, left-sided chest pain, and occasional palpitations. At cardiological assessment in April 1973, she was in sinus rhythm with a blood pressure of $100 / 60 \mathrm{mmHg}$ (13/8 kPa) and her jugular venous pressure was normal. There was a slight left ventricular heave. There was an apical fourth sound, and in the pulmonary area there was an ejection systolic murmur and a widely split second sound. A phonocardiogram showed the second sound split 0.03 to $0.05 \mathrm{~s}$ on inspiration. Electrocardiography showed left axis deviation and $T$ wave inversion in leads $\mathrm{V}_{4}$ to 6 . Chest radiography demonstrated moderate enlargement of the ventricular mass with slight enlargement of the right atrium, left atrium, and pulmonary artery.

Left and right heart catheterization was performed. This showed a pulmonary artery pressure of $26 / 9$ $\mathrm{mmHg}(4 / \mathrm{r} \mathrm{kPa})$, mean wedge pulmonary artery pressure of $14 \mathrm{mmHg}(2 \mathrm{kPa})$, and left ventricular enddiastolic pressure of $28 \mathrm{mmHg}(4 \mathrm{kPa})$. Indocyanine green dye injection into pulmonary artery with sampling from aorta showed a left-to-right shunt which was I 8 per cent of total pulmonary flow (Carter et al., 1960). Pulmonary flow was $0.06 \mathrm{l}$./s and the pulmonary to systemic flow ratio 1.2: r. Left ventricular angiography showed the left ventricle to be dilated with impaired contraction. The right coronary artery filled late. Judkins selective right coronary arteriography confirmed the large right coronary artery and there were prominent septal collaterals to the left coronary artery which filled retrogradely. The dye passed from the left coronary artery into the main pulmonary trunk (Fig.).

At operation it was planned to recreate the dual coronary system by performing a saphenous vein graft from the aorta to the anterior descending branch of the left coronary artery. It was found that the right coronary artery was approximately $\mathrm{I} \mathrm{cm}$ in diameter, with visible branches extending across towards the left coronary artery. The left coronary artery was also large and 


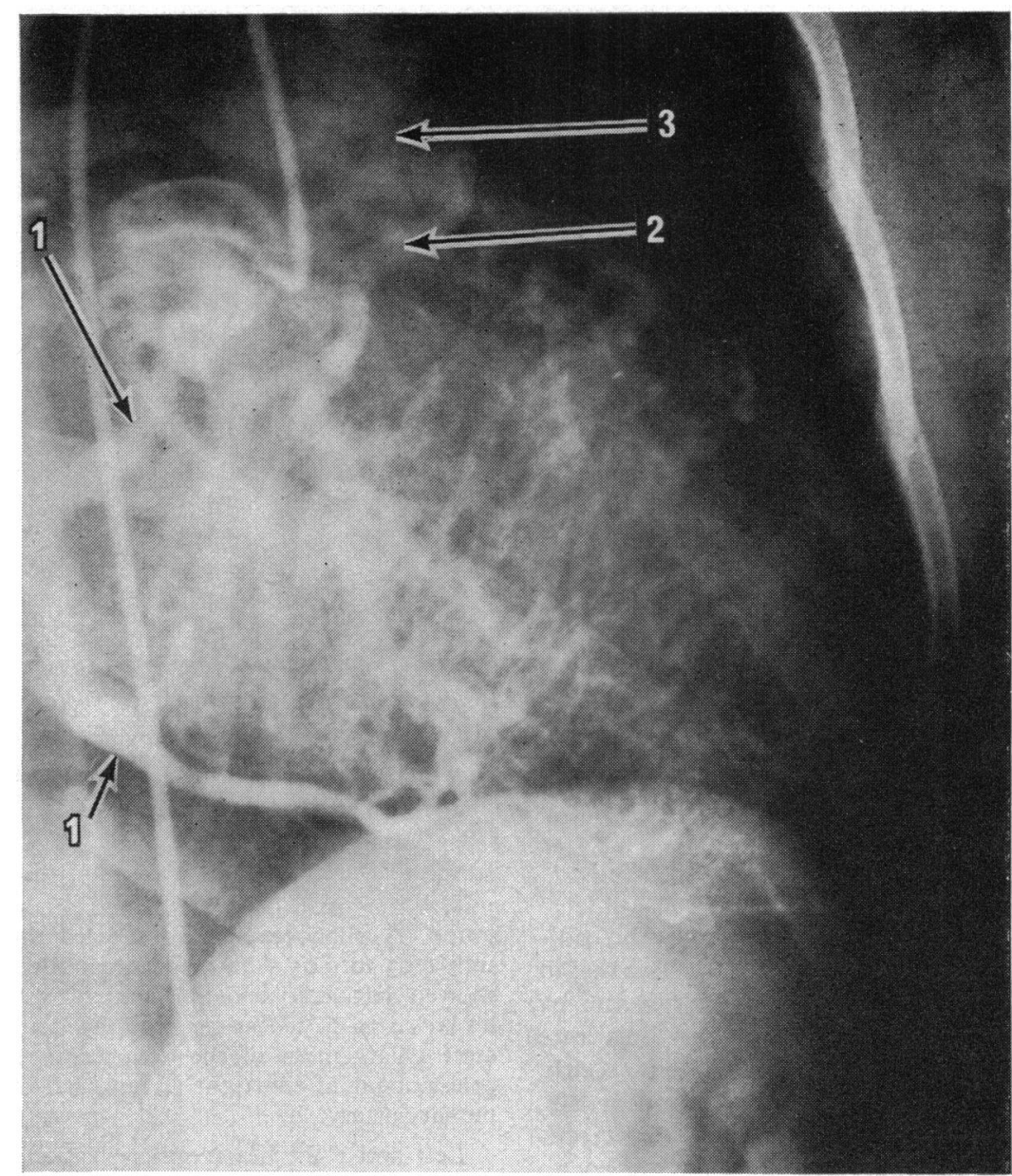

FIG. Right coronary angiogram. Arrows point to: I) the right coronary artery; 2) the circumflex branch of the left coronary artery; and 3) the pulmonary artery. The large collateral vessels are well seen.

arose posteriorly from above the posterior cusp of the pulmonary artery. The circumflex branch arose early, close to the pulmonary artery, and it was not possible to gain proximal control of the left coronary artery because of the fear of damaging the circumflex branch. It was, therefore, decided to suture the origin of the anomalous left coronary artery from inside the pulmonary artery after performing the distal end of the saphenous vein graft. On bypass the aorta was occluded to reduce bleeding from the saphenous-coronary anastomosis, but bleeding still occurred from the pulmonary artery end, making the anastomosis difficult. The pulmonary artery was then opened and the ostium of the anomalous pulmonary artery above the posterior cusp was obliterated with two layers of $4 / 0$ Ethiflex. The proximal anastomosis was then performed to the aorta. The flow through the graft, estimated with a flow-meter, was
$350 \mathrm{ml} / \mathrm{min}$. The aortic occlusion time before the closure of the left coronary artery origin was 75 minutes at $37^{\circ} \mathrm{C}$. Throughout the bypass the aortic pressure could not be raised above 35 to $40 \mathrm{mmHg}(4.66-5.33 \mathrm{kPa})$ despite adequate loading and pressor drugs. On attempting to come off bypass the left ventricle was unable to maintain an acceptable blood pressure, there was a high left atrial pressure, and the electrocardiogram showed widespread infarction. The patient died. At necropsy the part of the left ventricle supplied by the anomalous coronary artery was grossly fibrotic and the remaining muscle was infarcted.

\section{Discussion}

Reports of surgery carried out on an anomalous left coronary artery in adult life are relatively few. In a 
review of 140 cases, II6 infantile and 24 postinfantile, there were II adult cases (Wesselhoeft, Fawcett, and Johnson, 1968), none of whom was treated surgically. Of the II, 9 died suddenly, 5 after exertion, and 8 had had no previous cardiac symptoms. In another review of 30 post-infantile cases (Flamm et al., 1968), 12 died suddenly on exertion, usually in the third or fourth decade. The average life expectancy in the adult group was 35 years (George and Knowlan, 1959).

Because of the high risk of sudden death, operation is usually advised for anomalous coronary arteries. This is particularly urgent if arrhythmias are present (Wright et al., 1970).

The importance of the physiological shunt which can develop between the right coronary artery and the pulmonary artery has been stressed by Wright et al. (1970), and they described 2 cases of coronary artery steal in which the anastomotic vessels were not feeding the myocardium but acting as a drainage system. Both of these cases were improved by ligation of the anomalous left coronary artery at its pulmonary origin. The blood from the anomalous artery was found to be fully saturated and the pressure in it rose from $30 \mathrm{mmHg}$ to $75 \mathrm{mmHg}$ (4 to 10 $\mathrm{kPa}$ ) after clamping (Sabiston, Neill, and Taussig, 1960).

The surgical alternatives are to ligate the anomalous artery near to the pulmonary artery (Nadas, Gamboa, and Hugenholtz, 1964) with or without recreation of the dual coronary system, by connecting the artery to the aorta with a saphenous vein graft (Cooley, Hallman, and Bloodwell, I966). The latter has proved satisfactory in children, though long-term graft function was perfect in only I out of 6 cases (El Said et al., 1973). Dissection of the friable artery and the risk of circumflex artery damage can be avoided if the anomalous artery is closed from inside the pulmonary artery (Flamm et al., I968).

The surgical technique usually advocated in recent years is ligation of the anomalous left coronary artery and connexion of the distal artery to the aorta by a saphenous vein bypass graft (Cooley et al., 1966). The difficulties of carrying out such a procedure in an adult patient with a large shunt flowing through the coronary systems from aorta to pulmonary artery are emphasized by the case reported here.

While this patient was on bypass, the pulmonary artery pressure was zero, and, therefore, the shunting effect from the right coronary artery to the left coronary artery to the pulmonary artery was increased, and true myocardial blood flow decreased. This conspicuously lowered the aortic pressure during bypass, which also prevented adequate per- fusion of the ventricles even when the aortic clamp was off.

Time was also spent in attempting to isolate the proximal end of the left coronary artery, before it was realized that occlusion could not be performed without damaging the circumflex artery. The anomalous artery arose from the back of the pulmonary artery and had given off the circumflex artery in a position where access was extremely difficult, with large collateral vessels running to the right coronary artery around the base of the pulmonary artery anteriorly. Though the anastomosis of the saphenous vein graft had been adequate in terms of blood flow (350 $\mathrm{ml} / \mathrm{min}$ ), the myocardium had not been perfused satisfactorily during the procedure and widespread infarction led to death.

The anastomoses were large and visible and it is difficult to imagine achieving a better rate of flow down a saphenous vein graft than through the anastomoses from the enormous right coronary artery. The advantages of saphenous vein bypass are, therefore, small in a patient such as this. Ligation of the anomalous left coronary artery alone converts the heart into a one coronary system which can be compatible with a normal life span (Smith, 1950). If the anastomoses are small then ligation of the anomalous artery alone would obviously be wrong.

\section{References}

Bland, E. F., White, P. D., and Garland, J. (1933). Congenital anomalies of the coronary arteries: report of an unusual case associated with cardiac hypertrophy. American Heart Fournal, 8, 787 .

Brooks, H. St. John (1886). Two cases of an abnormal coronary artery of the heart arising from the pulmonary artery. Fournal of Anatomy and Physiology, 20, 26.

Carter, S. A., Bajec, D. F., Yannicelli, E., and Wood, E. H. (1960). Estimation of left-to-right shunt from arterial dilution curves. Fournal of Laboratory and Clinical Medicine, 55, 77.

Cooley, D. A., Hallman, G. L., and Bloodwell, R. D. (I966). Definitive surgical treatment of anomalous origin of left coronary artery from pulmonary artery. Indications and results. Fournal of Thoracic and Cardiovascular Surgery, 52, 798.

El Said, G. M., Ruzyllo, W., Williams, R. L., Mullins, C. E., Hallman, G. L., Cooley, D. A., and McNamara, D. G. (1973). Early and late result of saphenous vein graft for anomalous origin of left coronary artery from pulmonary artery. Circulation, 47 and 48, Suppl. 3, 2.

Flamm, M. D., Stinson, E. B., Hultgren, H. N., Shumway, N. E., and Hancock, E. W. (1968). Anomalous origin of the left coronary artery from the pulmonary artery. Circulation, 38, I13.

George, J. M., and Knowlan, D. M. (1959). Anomalous origin of the left coronary artery from the pulmonary artery in an adult. New England fournal of Medicine, 261, 993.

Hudson, R. E. B. (1965). Cardiovascular Pathology. Edward Arnold, London. 
Keith, J. D. (1959). The anomalous origin of the left coronary artery from the pulmonary artery. British Heart fournal, 21, I49.

Nadas, A. S., Gamboa, R., and Hugenholtz, P. G. (1964). Anomalous left coronary artery originating from the pulmonary artery. Report of two surgically treated cases with a proposal of hemodynamic and therapeutic classification. Circulation, 29, 167.

Sabiston, D. C., Neill, C. A., and Taussig, H. B. (1960). The direction of blood flow in anomalous left coronary artery arising from the pulmonary artery. Circulation, 22, 591.

Smith, J. C. (1950). Review of single coronary artery with report of two cases. Circulation, $\mathrm{x}, \mathrm{I} 168$.

Wesselhoeft, H., Fawcett, J. S., and Johnson, A. L. (1968).
Anomalous origin of the left coronary artery from the pulmonary trunk. Its clinical spectrum, pathology, and pathophysiology, based on a review of 140 cases with seven further cases. Circulation, 38, 403.

Wright, N. L., Baue, A. E., Baum, S., Blakemore, W. S., and Zinsser, H. F. (1970). Coronary artery steal due to an anomalous left coronary artery originating from the pulmonary artery. Fournal of Thoracic and Cardiovascular Surgery, 59, 46r.

Requests for reprints to M. V. Braimbridge, Esq., F.R.C.S., Department of Cardiothoracic Surgery, St. Thomas' Hospital, London SEI $7 \mathrm{EH}$. 